\title{
Intraseasonal Variation in Reproductive Effort: Young Males Finish Last
}

\author{
Tom H. E. Mason, ${ }^{1, \star}$ Philip A. Stephens, ${ }^{1}$ Stephen G. Willis, ${ }^{1}$ Roberta Chirichella, ${ }^{2}$ \\ Marco Apollonio, ${ }^{2}$ and Shane A. Richards ${ }^{1}$
}

1. School of Biological and Biomedical Sciences, University of Durham, South Road, Durham DH1 3LE, United Kingdom;

2. Department of Science for Nature and Environmental Resources, University of Sassari, via Muroni 25, I-07100 Sassari, Sardinia, Italy

Submitted May 11, 2012; Accepted July 5, 2012; Electronically published October 30, 2012

Online enhancement: appendixes.

\begin{abstract}
Age-dependent reproductive timing has been observed in females of a number of species; older females often breed earlier in the season and experience higher reproductive success as a result. However, to date, evidence for within-season variation in reproductive effort (RE) for males has been relatively weak. Males are expected to time RE in light of intraseasonal variations in the availability of receptive females and competition with other males. Young males, which are typically smaller and less experienced, might benefit from breeding later in the season, when male-male competition is less intense. Using a long-term data set of Alpine chamois Rupicapra rupicapra, we sought to evaluate the hypothesis that younger males allocate highest RE late in the breeding season, at a time when older male RE has decreased substantially. Our results support this hypothesis, which suggests that intraseasonal variation in RE may be an adaptive life-history trait for males as well as females.
\end{abstract}

Keywords: life histories, reproductive effort, chamois, ungulate, rut, competition.

\section{Introduction}

In a number of vertebrates, but particularly birds, older individuals breed earlier in the season than younger individuals (Perdeck and Cave 1992; Forslund and Part 1995). Earlier breeding often increases reproductive success (Sydeman et al. 1991; Verhulst and Tinbergen 1991), because earlier-born offspring can profit from greater resource availability (van Noordwijk et al. 1995) and longer growing seasons (Cote and Festa-Bianchet 2001; Feder et al. 2008). Furthermore, they may have a competitive advantage over later-born rivals (Nilsson 1989). Reproductive timing can also affect adults directly, because late breeders can experience greater time or energetic constraints after breeding (Nilsson and Svensson 1996). Age-

\footnotetext{
* Corresponding author; e-mail: t.h.mason@durham.ac.uk.
}

Am. Nat. 2012. Vol. 180, pp. 823-830. (C) 2012 by The University of Chicago. 0003-0147/2012/18006-53839\$15.00. All rights reserved.

DOI: $10.1086 / 668082$ dependent patterns of reproductive timing are generally attributed to increasing breeding competence with age as individuals become larger and more experienced (e.g., Forslund and Part 1995). Young breeders may also be limited energetically because of their smaller size; breeding later in the season allows time for them to acquire sufficient energy reserves (Schultz et al. 1991; Cargnelli and Neff 2006).

To date, the vast majority of studies have focused on reproductive timing in females; however, life-history tradeoffs are also expected to drive age-dependent patterns in male reproductive phenology (e.g., Mysterud et al. 2008). Despite the advantages of early breeding, younger, smaller, or less experienced males might benefit from delaying breeding until later in the season. During the peak breeding season, when female receptivity is at its highest, malemale competition can be intense, and breeding can be monopolized by a small number of dominant males (Clutton-Brock et al. 1985). Young males are known to increase their reproductive effort (RE; allocation of resources to current reproduction) in years when older males are scarcer (Singer and Zeigenfuss 2002). This might also hold true within a season if older males exhaust their energy stores and cease to compete effectively before the end of the period of female receptivity. However, although malemale competition is known to influence male $\mathrm{RE}$ in a range of taxa (e.g., Neff et al. 2004; Galimberti et al. 2007), there is currently little evidence for its influence on the timing of male RE across the breeding season. Indeed, in some species there is no support for an effect of experience on reproductive timing (Ridgway et al. 1991). Intriguingly, there is some support from a male mammal; in populations of red deer Cervus elaphus at low density, primeaged male peak RE coincides with peak female receptivity, whereas young male RE peaks slightly later in the season 
(Mysterud et al. 2008). Whether this male life-history strategy occurs more widely among mammals is unknown.

Alpine chamois Rupicapra rupicapra are polygynous, although relatively sexually monomorphic, mountain ungulates (Couturier 1938; Kramer 1969; Knaus and Schröder 1983). Male chamois allocate RE annually to a short rutting season each autumn, during which they defend small, clustered territories and guard estrus females from rivals (Kramer 1969; von Hardenberg et al. 2000). Intriguingly, field observations of breeding chamois during the 2011 rut in our study area in the central-eastern Italian Alps suggest that peak breeding activity of younger males occurs near the end of the rut, much later than that of older males, which supports an age-dependent pattern of reproductive timing in this species (fig. 1). However, because of the small sample size of observations, which were limited to a single year, it is unclear whether this pattern of activity occurs consistently across years for this population.

Male chamois are capital breeders (Stephens et al. 2009) that significantly reduce their food intake during their breeding season and depend on stored energy to breed (Willisch and Ingold 2007). In capital breeders, RE is strongly related to the size of an individual's energy store (Doughty and Shine 1997), and body mass loss rates can be used as estimates of RE (Yoccoz et al. 2002; Mysterud et al. 2005). In Alpine chamois, breeding males experience pronounced mass loss during the rut, whereas the mass loss rates of nonbreeding males and females during the same period are much lower (Mason et al. 2011), which supports the use of mass loss rate as an index of RE in this species. On the basis of this established link between $\mathrm{RE}$ and rate of mass loss, we assess support for the prediction that young male chamois in our system increase their RE later in the rut, when larger, older males begin to reduce their RE. We do this by taking advantage of a long-term (32-year) data set of hunting records taken during the rutting season and by estimating patterns of mass change across age classes for three neighboring populations.

\section{Material and Methods}

Study Area

Data were collected in the central-eastern Italian Alps, across a $1,333-\mathrm{km}^{2}$ area of Trento Province $\left(46^{\circ} 02^{\prime} \mathrm{N}\right.$, $\left.10^{\circ} 38^{\prime} \mathrm{E}\right)$. The elevation of the study area ranges from 52 to $3,558 \mathrm{~m}$ asl, with a mean altitude of $1,586 \mathrm{~m}$ asl. The study area is forested up to the tree line at approximately 2,000 m, above which habitat consists of Alpine meadows and open rock faces. The study area is made up of six chamois hunting districts, which are separately managed

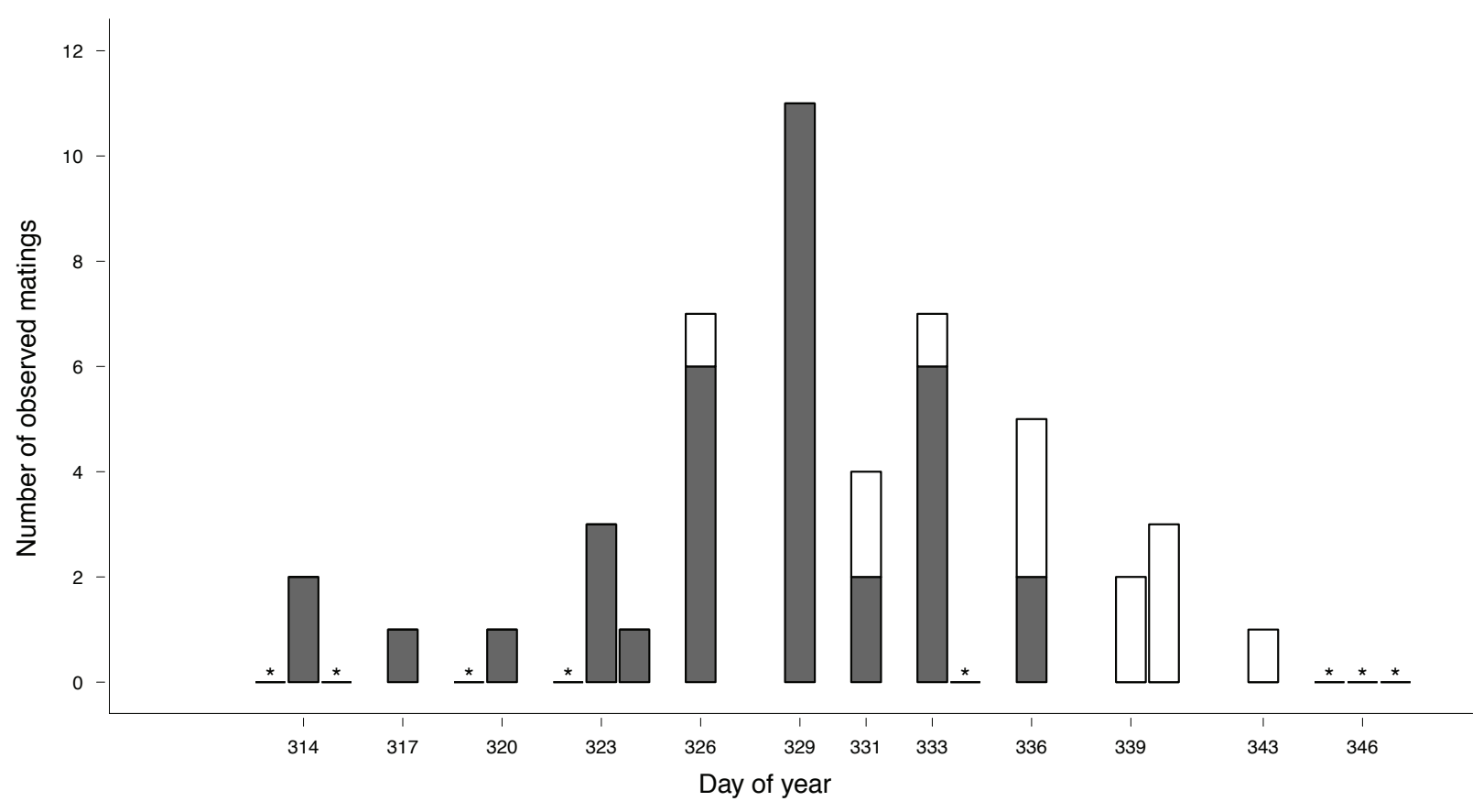

Figure 1: Variation in the frequency of observed mating events involving young (3-5 years of age; white bars) and old ( $\geq 6$ years; gray bars) males over time, during the rut. Asterisks indicate days on which surveys were performed but no mating events were observed. 
areas with independent hunting quotas (see Mason et al. 2011 for more information).

\section{Mating Data}

Data were collected on the frequency of mating events during the rutting season of autumn 2011. Data collection started on October 29 (day 302) and ended on December 13 (day 347). Two survey sites were chosen within the study area, both consisting of a high proportion of open habitat and known to be used by rutting chamois. The survey sites were visited every few days during the season, and visual scans of all individuals in the area were performed at regular intervals during the day using spotting scopes and binoculars. All observed mating events were recorded, and the ages of the males involved were classified as $3-5$ years or $\geq 6$ years on the basis of their body size and horn length (Knaus and Schröder 1983). Observer effort was constant throughout each day of data collection. Because of small sample sizes, data were aggregated across both sites (fig. 1).

\section{Body Mass Data}

Data were collected on the eviscerated body mass, sex, age, and date shot of male Alpine chamois culled over 38 consecutive hunting seasons between 1979 and 2010. Chamois are hunted with rifles every year from mid-September to the end of December. Hunting is controlled through licenses issued by local wildlife boards. Area-wide hunting quotas are set for specific age classes in each sex (see Mason et al. 2011). There is little potential for artificial selection by hunters (e.g., by shooting the largest individuals at the start of the season), because flight distances (distance from the hunter when the chamois takes flight) in these hunted populations are large because of the generally open habitat. As such, although trophy hunting is practiced in Trento Province, hunters have limited shooting opportunities per day and will typically shoot the first animal of a suitable age class that they encounter. Also, because both males and females are trophy hunted, we would expect to see pronounced patterns of decreasing mass with season in adults of both sexes if artificial selection was occurring. However, this is not the case in females (Mason et al. 2011). Furthermore, there is no evidence in our study area of hunter selection for larger-bodied age classes earlier in the season, which might be the case if there were strong hunter selection for larger body mass (Mason et al. 2011).

Ages were estimated from counts of horn growth annuli (Schröder and Von Elsner-Schak 1985). Males varied between 1 and 19 years old. Data on males older than 13 years were limited and therefore were excluded from our analysis. Dates of shooting were converted to the Julian calendar and ranged from day 252 to 351 (September 9December 17). This time period encompasses a prerut period as well as the entire rut (Mason et al. 2011). We analyzed data from three of the six hunting districts in our study area: Adamello, Presanella, and Brenta. The remaining three districts contained too few data to assess RE reliably across a range of ages. Despite the strict criteria above, our sample size was still large (12,893 individuals).

\section{Statistical Analysis \\ Model of Within-Season Body Mass Dynamics}

We sought to characterize age-dependent, temporal patterns of male mass change across the rutting season. Let $\bar{m}_{a}(s, y, t)$ be the mean mass of an individual of age $a$ in site (i.e., hunting district) $s$ on day $t$ of year $y$. Change in mass throughout the season is governed by

$$
\frac{d \bar{m}_{a}}{d t}=C_{a}(s, y, t) \bar{m}_{a}
$$

where $C_{a}$ is the relative rate of mass change of individuals of age $a$. If the mean mass on day 252 (the earliest shot date recorded) is $\bar{m}_{a, y, 252}$, then the solution to equation (1) is

$$
\bar{m}_{a}(s, y, t)=\bar{m}_{a, s, y, 252} \exp \left(\int_{\tau=252}^{t} C_{a}(s, y, \tau) d \tau\right) .
$$

Here, we assumed that $C_{a}$ can be partitioned into a baseline rate, denoted $F_{a}(s, t)$, and a year-dependent offset, denoted $w_{a, s, y}$, which reflects annual variation due to environmental changes or factors such as population density (Yoccoz et al. 2002; Mysterud et al. 2008). Also, we assumed that mean mass on day 252 can vary across years for age $a$ in site $s$ by factor $z_{a, s, y}$. Thus, the expected mass is

$$
\begin{gathered}
\bar{m}_{a}(s, y, t)=z_{a, s, y} \bar{m}_{a, s, 252} \exp \left(\int_{\tau=252}^{t} F_{a}(s, \tau)+w_{a, s, y} d \tau\right) \\
=z_{a, s, y} \bar{m}_{a, s, 252} \exp \left(w_{a, s, y}(t-252)\right) \exp \left(\int_{\tau=252}^{t} F_{a}(s, \tau) d \tau\right),
\end{gathered}
$$

where $\bar{m}_{a, s, 252}$ is the average mass of individuals of age $a$ at site $s$ on day 252 across the 32-year span of the study. Because we have no a priori prediction regarding the functional form of $F_{a}$ with respect to day $(t)$, we considered five possibilities: constant, linear, quadratic, cubic, and 
double cubic spline, each spanning day 252 to 351 (for equations of the functions we used to describe $F$, see app. A, available online).

\section{Model Fitting and Model Selection}

Despite having access to a large data set of male masses, sample sizes were much reduced when data were subdivided among ages, sites, and years. Such low sample sizes can result in high uncertainty in parameter estimates. Thus, we made use of our previous analyses (Mason et al. 2011), which indicated relatively low variation in patterns of mass change among adjacent ages. We combined our age data into four age classes: 1-2-year-old individuals (nonbreeders), 3-4-year-old individuals (young breeders), 5-6-year-old individuals (early prime age), and 7-13-yearold individuals (late prime age). We estimated age-dependent parameters separately for each of these age classes, which we distinguish using the subscript $A$.

We assumed that the variation in the mass data for age $a$ individuals at site $s$ about the modeled mean is normally distributed with variance $\sigma_{a, s}$. Thus, the log likelihood of the model parameters associated with age class $A$ at site $s$, denoted $\theta_{A, s}$ given all the data,

$$
\begin{gathered}
\operatorname{LL}\left(\theta_{A, s}\right)=\sum_{a \in A} \sum_{y} \sum_{j}\left\{-\frac{1}{2} \ln (2 \pi)-\ln \left(\sigma_{a}\right)\right. \\
\left.+\frac{1}{2}\left[\frac{\bar{m}_{A}\left(s, y, t_{a, s, y, j}\right)-m_{a, s, y, j}}{\sigma_{a, s}}\right]\right\},
\end{gathered}
$$

where $m_{a, s, y, j}$ and $t_{a, s, y, j}$ are the mass and the day of the $j$ th aged $a$ individual sampled in year $y$ at site $s$, respectively. For each age class at a site, we fitted the five functional forms for $F$ proposed above using maximum likelihood and identified the most parsimonious fit using the Akaike Information Criterion (Burnham and Anderson 2002; Richards 2008). Uncertainty in our body mass predictions was assessed by fitting 1,000 bootstrapped replicates stratified by year, site, and age (Efron and Tibshirani 1991). Random sampling, stratified within season across four time periods (determined by the quartiles of available data with respect to time), was used to produce replicates with a representative spread of data. Statistical analyses were performed using R, version 2.12.0 (R Development Core Team 2011).

\section{Results}

Model selection indicates that the relative rate of change in male mass during the rutting season varies both with time and age; in no age class is the constant growth model the most parsimonious (fig. 2, app. B, available online). Importantly, our model formulation is clearly able to describe the observed variation in body mass during the breeding season for all age classes (fig. 3).

In each age class, there is a highly consistent temporal pattern of mass change among the three sites. In 1-2-yearold individuals, the rate of mass change remains close to 0 throughout the season (fig. $2 A, 2 E, 2 I$ ). In 3-4-year-old individuals, this rate is near 0 at the start of the season before becoming increasingly negative throughout the rest of the season (fig. $2 B, 2 F, 2 J$ ). Such extended periods of mass loss are suggestive of RE. Importantly, in all sites, mass loss rates among 3-4-year-old individuals continue to increase beyond the date on which the majority of rutting activity is generally thought to conclude (approximately day 340; Mason et al. 2011). In contrast, in both older age classes, the rate of mass loss peaks at approximately day 325 , after which the rate of mass loss decreases. Interestingly, there is even a short period of mass gain at the end of the year for the older individuals (fig. $2 C, 2 D$, $2 \mathrm{G}, 2 \mathrm{H}, 2 \mathrm{~K}, 2 \mathrm{~L}$ ). These findings suggest a relatively welldefined rutting period in older males, which is followed by a period of mass recovery. The confidence intervals suggest that, although uncertainty increases toward the temporal limits of our data, the observed patterns are robust.

\section{Discussion}

Here, we sought support for the hypothesis that, relative to older males, younger males should allocate RE later in the breeding season, when male-male competition may be less intense. For chamois, our data indicate that the timing of mass loss during the breeding season, which is a reliable measure of RE, varies strikingly between young and old breeding males (fig. 2). Males of 3-4 years of age experience their highest mass loss rates 13-27 days later in the season than older males, at a time when the loss rates of older males are significantly reduced (fig. 2). As such, our results suggest that young chamois males allocate peak RE late in the season, when older males are significantly reducing their RE, which provides considerable support for our hypothesis. Interestingly, this intraseasonal pattern is highly consistent across the three districts investigated, despite considerable variation in how males in these populations allocate RE across their lives (Mason et al. 2011).

Our results concur with field observations from our study area. Specifically, the frequency of mating events involving young males increases toward the end of the rutting season (fig. 1), in keeping with our estimates of young male RE (fig. $2 B, 2 F, 2 J$ ). In contrast, peak mating activity in older males occurs much earlier, consistent with 

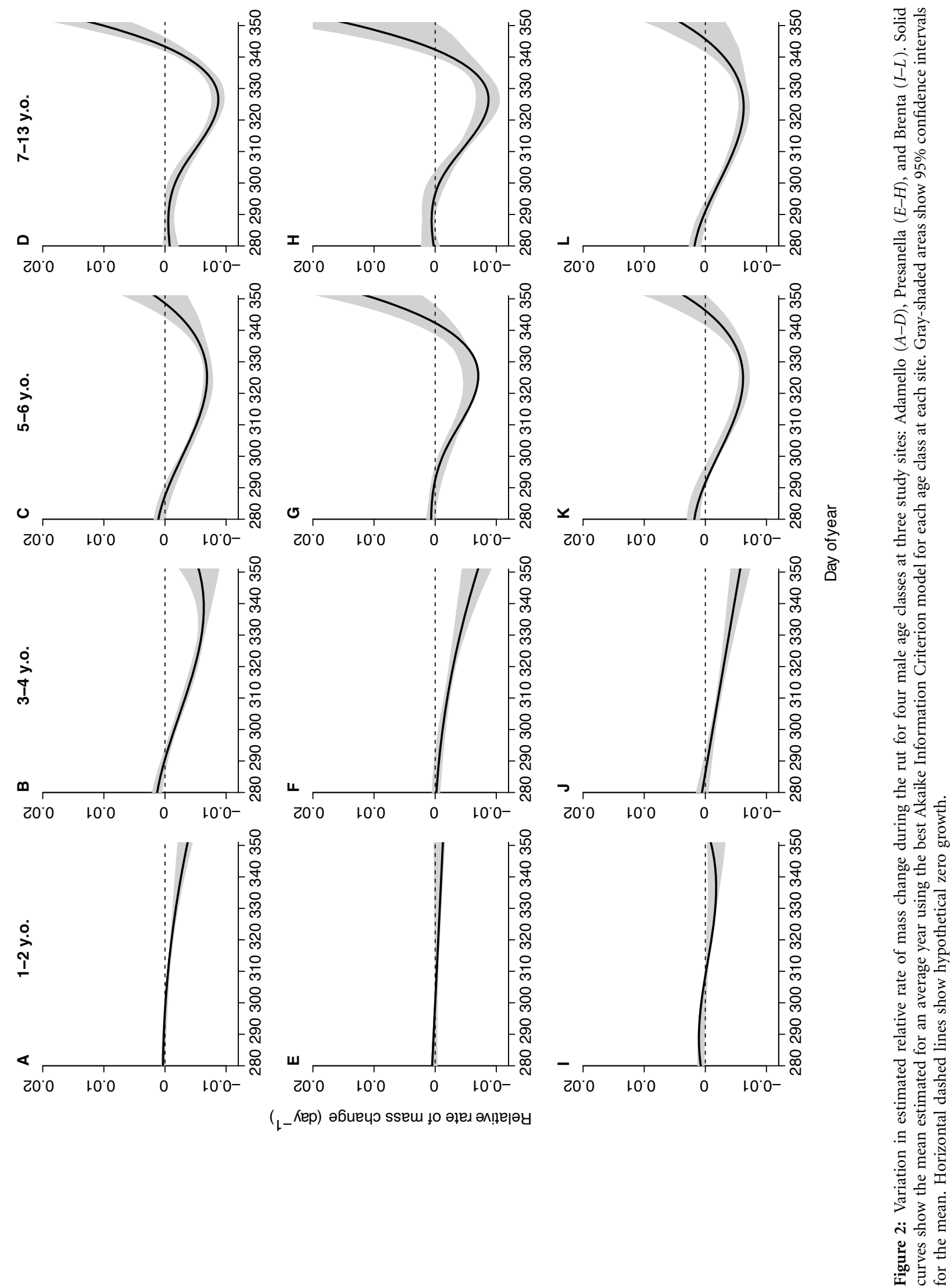

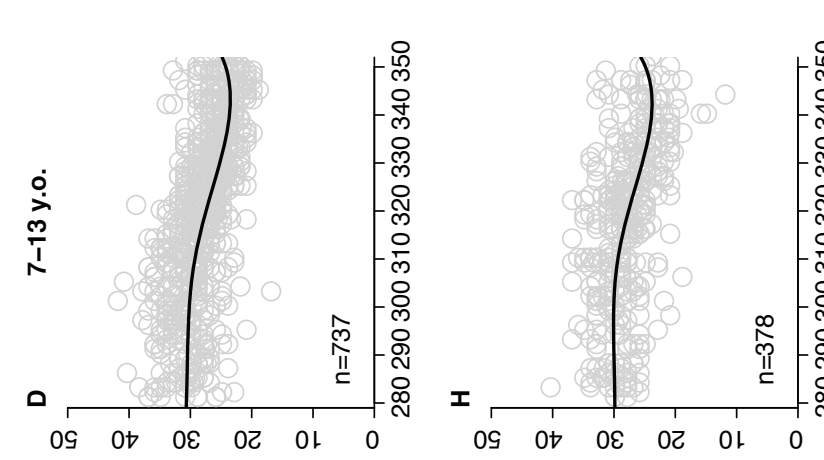

$\cong$

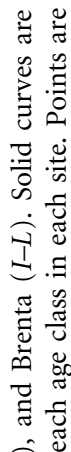
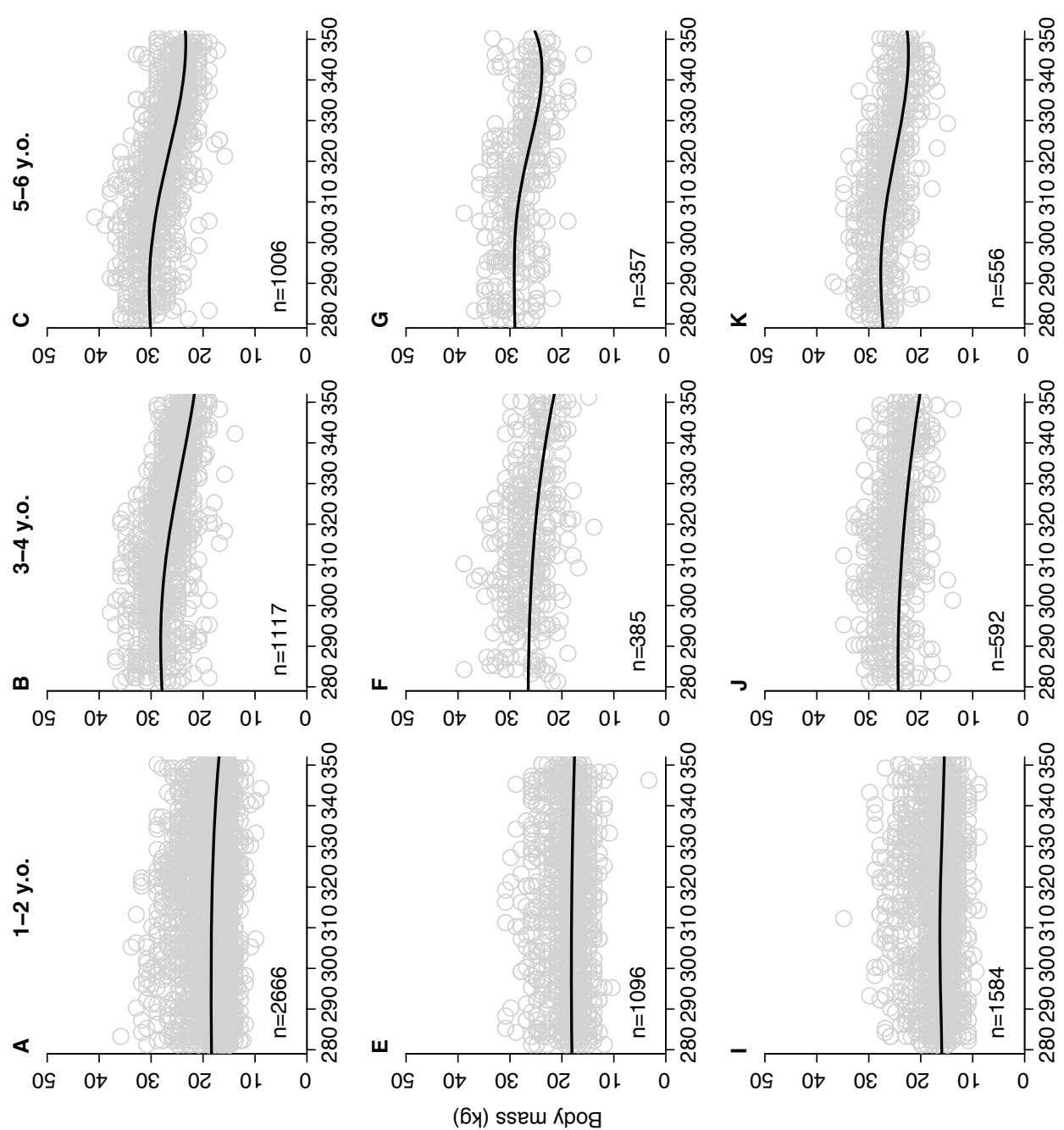
our estimates of peak RE for older males (fig. $2 C, 2 D, 2 G$, $2 H, 2 K, 2 L$ ). This agreement strongly suggests that the observed high rates of young male mass loss late in the season are indeed a result of RE, rather than, for instance, an inability to halt mass loss following the rut. Reduced competition from older males late in the season could drive an adaptive life-history strategy, in which young males could be rewarded with late mating opportunities. Males that are 3-4 years old are 7\%-10\% lighter than older age classes and are generally less experienced (males are sexually mature at 3-4 years; Couturier 1938; Knaus and Schröder 1983). Also, chamois males are more likely to defend a breeding territory successfully if they occupied it in the previous year (von Hardenberg et al. 2000). As such, young males may struggle to compete for territory ownership and could benefit from delaying peak RE until later in the season, when male-male competition is reduced. Importantly, our findings strongly support those of Mysterud et al. (2008), who theorized that exhaustion of prime-aged males was driving a similar reproductive strategy in young red deer. There is some evidence that late breeding by subordinate males can be profitable in ungulates: in Soay sheep Ovis aries, for example, although there are no data on the intraseasonal timing of RE, the siring rate of smaller males increases toward the end of the season, in part due to sperm depletion in dominant males (Preston et al. 2001).

In our study, males that are 5-6 and 7-13 years old appear to significantly reduce their RE late in the season, eventually pulling out of the rut, as shown by mass gains (fig. $2 \mathrm{C}, 2 \mathrm{D}, 2 \mathrm{G}, 2 \mathrm{H}, 2 \mathrm{~K}, 2 \mathrm{~L}$ ), at a time when few estrus females are thought to still be present in our study area. It is likely that this withdrawal is necessary because of exhaustion following a long period of reduced food intake (Willisch and Ingold 2007). Indeed, there is evidence that males in these populations cease rutting once their mass drops below a particular threshold (Mason et al. 2011). Males that are 7-13 years old appear to stop rutting slightly earlier and gain more mass after rut than males that are 5-6 years old. By quitting earlier, the oldest and most experienced individuals have more time to prepare for the coldest months. Body mass is positively correlated with overwinter survival in ungulates because of thermoregulatory costs (Berube et al. 1999; Loison et al. 1999), and being in poor condition following the rut may put individuals at a greater risk of mortality. Males that are 3-4 years old continue to lose mass at a high rate at the end of the year (fig. $2 B, 2 F, 2 J$ ), apparently trading off any heightened mortality risk against the benefit of reproduction late in the season.

We have identified strong age-dependent patterns in the timing of mass loss across the breeding season for chamois, and it is likely that this reflects variation in how different age classes allocate RE over time. This suggests that agedependent variation in reproductive timing can exist in males as well as in females. In chamois, this variation appears to be a result of an adaptive life-history strategy in young males, which favor delaying peak RE until older males have significantly reduced their RE, despite there being fewer receptive females present at this time. Our findings highlight an important life-history strategy in subordinate individuals and add substantial support to a similar result involving another ungulate (Mysterud et al. 2008). We propose that late breeding by young males could be a general phenomenon in ungulates.

\section{Acknowledgments}

We are grateful to Trento Province, the Adamello Brenta Nature Park, and the Associazione Cacciatori Trentini (the regional hunting association), as well as to the hunting reserve of Regole Spinale e Manez, for supplying data. We are indebted to A. Brugnoli, M. Rocca, and all of the game wardens who collected Alpine chamois measurements. We also thank D. Rambaldini for support in the collection of the field data. We are grateful to two anonymous reviewers for insightful comments on an earlier draft. T.H.E.M. is supported by a Natural Environment Research Council Doctoral Training grant (NE/H524573/1) under the supervision of S.G.W. and P.A.S.

\section{Literature Cited}

Berube, C. H., M. Festa-Bianchet, and J. T. Jorgenson. 1999. Individual differences, longevity, and reproductive senescence in bighorn ewes. Ecology 80:2555-2565.

Burnham, K. P., and D. R. Anderson. 2002. Model selection and multimodel inference: a practical information-theoretic approach. Springer, New York.

Cargnelli, L. M., and B. D. Neff. 2006. Condition-dependent nesting in bluegill sunfish Lepomis macrochirus. Journal of Animal Ecology 75:627-633.

Clutton-Brock, T. H., F. E. Guinness, and S. D. Albon. 1985. Red deer: the behaviour and ecology of two sexes. Edinburgh University Press, Edinburgh.

Cote, S. D., and M. Festa-Bianchet. 2001. Birthdate, mass and survival in mountain goat kids: effects of maternal characteristics and forage quality. Oecologia (Berlin) 127:230-238.

Couturier, M. 1938. Le chamois. Arthaud, Grenoble.

Doughty, P., and R. Shine. 1997. Detecting life history trade-offs: measuring energy stores in "capital" breeders reveals costs of reproduction. Oecologia (Berlin) 110:508-513.

Efron, B., and R. Tibshirani. 1991. Statistical data analysis in the computer age. Science 253:390-395.

Feder, C., J. G. A. Martin, M. Festa-Bianchet, C. Berube, and J. Jorgenson. 2008. Never too late? consequences of late birthdate for mass and survival of bighorn lambs. Oecologia (Berlin) 156: 773-781. 
Forslund, P., and T. Part. 1995. Age and reproduction in birds: hypotheses and tests. Trends in Ecology \& Evolution 10:374-378.

Galimberti, F., S. Sanvito, C. Braschi, and L. Boitani. 2007. The cost of success: reproductive effort in male southern elephant seals (Mirounga leonina). Behavioral Ecology and Sociobiology 62:159-171.

Knaus, W., and W. Schröder. 1983. Das Gamswild. Paul Parey, Berlin.

Kramer, A. 1969. Soziale Organisation und Sozialverhalten einer Gemspopulation Rupicapra rupicapra der Alpen. Z. Tierpsychol. 26:889-964.

Loison, A., R. Langvatn, and E. J. Solberg. 1999. Body mass and winter mortality in red deer calves: disentangling sex and climate effects. Ecography 22:20-30.

Mason, T. H. E., R. Chirichella, S. A. Richards, P. A. Stephens, S. G. Willis, and M. Apollonio. 2011. Contrasting life histories in neighbouring populations of a large mammal. PLoS ONE 6:e28002.

Mysterud, A., C. Bonenfant, L. E. Loe, R. Langvatn, N. G. Yoccoz, and N. C. Stenseth. 2008. The timing of male reproductive effort relative to female ovulation in a capital breeder. Lournal of Animal Ecology 77:469-477.

Mysterud, A., E. J. Solberg, and N. G. Yoccoz. 2005. Ageing and reproductive effort in male moose under variable levels of intrasexual competition. Journal of Animal Ecology 74:742-754.

Neff, B. D., L. M. Cargnelli, and I. M. Cote. 2004. Solitary nesting as an alternative breeding tactic in colonial nesting bluegill sunfish (Lepomis macrochirus). Behavioral Ecology and Sociobiology 56: 381-387.

Nilsson, J. A. 1989. Establishment of juvenile marsh tits in winter flocks: an experimental study. Animal Behaviour 38:586-595.

Nilsson, J. A., and E. Svensson. 1996. The cost of reproduction: a new link between current reproductive effort and future reproductive success. Proceedings of the Roval Society B: Biological Sciences 263:711-714.

Perdeck, A. C., and A. J. Cave. 1992. Laying date in the coot: effects of age and mate choice. Journal of Animal Ecology 61:13-19.

Preston, B. T., I. R. Stevenson, J. M. Pemberton, and K. Wilson. 2001. Dominant rams lose out by sperm depletion: a waning success in siring counters a ram's high score in competition for ewes. Nature 409:681-682.

R Development Core Team. 2011. R: a language and environment for statistical computing. R Foundation for Statistical Computing, Vienna, Austria.
Richards, S. A. 2008. Dealing with overdispersed count data in applied ecology. Journal of Applied Ecology 45:218-227.

Ridgway, M. S., B. J. Shuter, and E. E. Post. 1991. The relative influence of body size and territorial behaviour on nesting asynchrony in male smallmouth bass, Micropterus dolomieui. $\underline{\text { Journal }}$ of Animal Ecology 60:665-681.

Schröder, W., and I. Von Elsner-Schak. 1985. Correct age determination in chamois. In S. Lovari, ed. The biology and management of mountain ungulates. Croom Helm, London.

Schultz, E. T., L. M. Clifton, and R. R. Warner. 1991. Energetic constraints and size-based tactics: the adaptive significance of breeding-schedule variation in a marine fish (Embiotocidae: $M i$ crometrus minimus). American Naturalist 138:1408-1430.

Singer, F. J., and L. C. Zeigenfuss. 2002. Influence of trophy hunting and horn size on mating behavior and survivorship of mountain sheep. Journal of Mammalogy 83:682-698.

Stephens, P. A., I. L. Boyd, J. M. McNamara, and A. I. Houston. 2009. Capital breeding and income breeding: their meaning, measurement, and worth. Ecology 90:2057-2067.

Sydeman, W. J., H. R. Huber, S. D. Emslie, C. A. Ribic, and N. Nur. 1991. Age-specific weaning success of northern elephant seals in relation to previous breeding experience. Ecology 72:2204-2217.

van Noordwijk, A. J., R. H. McCleery, and C. M. Perrins. 1995. Selection for the timing of great tit breeding in relation to caterpillar growth and temperature. Journal of Animal Ecology 64:451-458.

Verhulst, S. and J. M. Tinbergen. 1991. Experimental evidence for a causal relationship between timing and success of reproduction in the great tit (Parus major). Journal of Animal Ecology 60:269-282. von Hardenberg, A., P. Bassano, A. Peracino, and S. Lovari. 2000. Male Alpine chamois occupy territories at hotspots before the mating season. Ethology 106:617-630.

Willisch, C. S., and P. Ingold. 2007. Feeding or resting? the strategy of rutting male Alpine chamois. Ethology 113:97-104.

Yoccoz, N. G., A. Mysterud, R. Langvatn, and N. C. Stenseth. 2002. Age- and density-dependent reproductive effort in male red deer. Proceedings of the Roval Society B: Biological Sciences 269:15231528.
Associate Editor: Peter D. Taylor Editor: Judith L. Bronstein

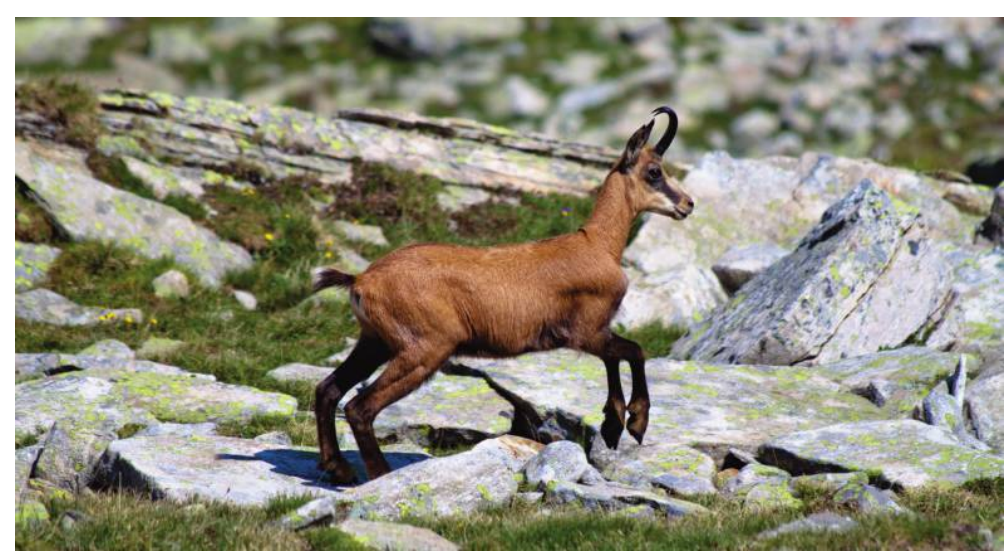

Male Alpine chamois (Rupicapra rupicapra) in pursuit of a rival. Photograph by T. H. E. Mason. 